Abstracta Iranica Abstracta Iranica

Revue bibliographique pour le domaine irano-aryen

Volume 25 | 2004

Comptes rendus des publications de 2002

\title{
Indo-Iranian Languages and Peoples. (Proceedings of the British Academy), Londres, 2002, 296 p.
}

\section{Étienne de La Vaissière}

\section{(2) OpenEdition}

1 Journals

Édition électronique

URL : http://journals.openedition.org/abstractairanica/4125

DOI : 10.4000/abstractairanica. 4125

ISSN : 1961-960X

\section{Éditeur :}

CNRS (UMR 7528 Mondes iraniens et indiens), Éditions de l'IFRI

\section{Édition imprimée}

Date de publication : 15 mai 2004

ISSN : 0240-8910

\section{Référence électronique}

Étienne de La Vaissière, «Indo-Iranian Languages and Peoples. (Proceedings of the British Academy), Londres, 2002, 296 p. », Abstracta Iranica [En ligne], Volume 25 | 2004, document 28, mis en ligne le 15 mars 2006, consulté le 25 septembre 2020. URL : http://journals.openedition.org/abstractairanica/ 4125 ; DOI : https://doi.org/10.4000/abstractairanica.4125

Ce document a été généré automatiquement le 25 septembre 2020.

Tous droits réservés 


\title{
Indo-Iranian Languages and Peoples. (Proceedings of the British Academy), Londres, 2002, 296 p.
}

\author{
Étienne de La Vaissière
}

1 Ce volume fera l'objet d'un c.r. dans St. Ir. Pour l'Asie centrale signalons notamment : F. Grenet, «Regional Interaction in Central Asia and North-West India in the Kidarite and Hephtalite Period », pp. 203-224, article dans lequel l'A. précise sa chronologie des royaumes kidarites (en plaçant Kidara vers 430), présente des particularités de l'iconographie ephtalite et ses rapports avec la période kidarite, enfin propose de situer Huolu, la capitale des ephtalites tardifs non loin de Surkh-Kotal (Qala'a-i Ghûrî). Notons aussi : N. Sims-Williams, «Ancient Afghanistan and its invaders: Linguistic evidence from the Bactrian documents and inscriptions», pp. 225-242, article dans lequel l'A. examine les apports en bactrien liés aux conquêtes successives de la Bactriane (héritage achéménide, grec, kouchan, indien, sassanide, ephtalite, chinois, turc) puis revient sur la question des noms des premiers rois kouchans, en privilégiant l'hypothèse sace. On notera au passage qu'il est douteux que le mot yabgu provienne du chinois Xihou (pp. 229-230, suivant à tort Humbach, Baktrische Sprachdenkmäler, 1, 1966, pp. 24-8), le titre étant attesté, notamment chez les Wusun, bien avant que les Han le donnent pour la première fois. Il n'est pas certain non plus qu'il faille faire revivre l'hypothèse de Bivar sur l'équation Asiani-Kouchans: Trogue Pompée écrit au plus tard au début du règne de Tibère (peut-être plus tôt, le dernier évènement d'histoire parthe mentionné date de 10 av. n.è. est c'est la remise en otage à Auguste des fils de Phraate IV) et n'a pu enregistrer la soumission des quatre autres Xihou par Kujula Kadphisès. G.-J. Pinault, "Tocharian and Indo-Iranian: Relations between two linguistic areas », pp. 243-284, examine à la lumière des nouvelles données sur la langue bactrienne la question complexe des apports bactriens en Tokharien (étude sur des cas précis, «droite/ gauche », « chef » et « gratitude » en tokharien). 
INDEX

Thèmes : 2.1. Langues anciennes

AUTEURS

ÉTIENNE DE LA VAISSIÈRE

EPHE - ENS - Paris 